\title{
Optimal Utilization of Low Grade Ores in Anqian Mining Company
}

\author{
Lihua Luan ${ }^{1}$, Lianjun Guo ${ }^{1 *}$, Chi Yang ${ }^{1}$, Daning Zhang ${ }^{1}$, Pengfei Pan ${ }^{2}$, Houguang Sun ${ }^{2}$ and Donglin Xu ${ }^{2}$ \\ ${ }^{1}$ University of Science and Technology Liaoning, Anshan, Liaoning, China \\ ${ }^{2}$ Anqian mining company, Anshan, Liaoning, China
}

\begin{abstract}
Based on the introduction of production technology of Anqian mining company, the stope ore mass distribution was analyzed in detail. The processability indexes of different grade ores were obtained with magnetic tube whereas the grinding time, concentrate grade and concentrate yield were measured. On the basis of digital ore deposit model which integrates ore natural attributes and processing attributes, two stages of ore blending optimization models were established. The first stage model sought the minimum of stope ore transportation cost under the restraints of output ore grade and stope production. The second stage was a system optional model that aimed at the furthest use of resources meeting not only the production constraints of mining field and process field but also ore beneficiability and the system output requirements of the concentrate grade. Lastly, the solving method of big M simplex algorithm was discussed and used in production.
\end{abstract}

Keywords: low grade ore, optimizing ore blending, ore separability, big M algorithm, ore blending model

\section{Foreword}

China is the biggest iron ore consumption market. But most of iron ore deposits in china possess such features as low grade, complex compositions, weak magneticity and refractoriness. Under the current economic and technical conditions, rational utilization of low-grade and refractory iron ore is strongly needed to improve the utilization ratio of mineral resources and keep mine development sustainable (Lei 2011). In recent years, the domestic research institutions and mines made a lot of achievements of rational development and utilization of low grade iron ore resources in the beneficiation technology and equipment, high and low grade balance, cost and tax analysis (Wang and Zhao 2013, Zhang 2014, Zhu and Li 2014), laying the foundation for reasonable utilization of low grade iron ore.

In this paper, Anqian mining company is taken as an example in which the production conditions, raw ore quality control, different grade of ore processability, and ore blending optimization mode in mining pit and processing plant were discussed to achieve the maximum utilization of low-grade refractory ores under the economical and reasonable conditions. This will ensure the stable operation of mining joint ventures and maximize the enterprise's production life and therefore, maximize the economic and social benefits in the enterprise life cycle.

\section{Introduction of Production Process of Anqian Mining Company}

As a mining joint venture, Anqian mining company has a stripping and mining capacity of 40 million tons totally, including 14 million tons of iron ore and the raw ore processing capacity of 8.34 million tons.
By the end of 2011 the geological reserve of iron ore reached 1.18 billion tons and the amount of ore in open pit is 210 million tons. The main type of ore is hematite, which is divided into industrial grade ore and low-grade ore, according to industrial indexes. The disclosed grade is 24.5\%. The stope is composed of three mines of $\mathrm{Xu}$ DongGou, Dumb Ling, West Back. Ore is transported by the truck- crushing - tape system (The truck - stationary crushing station - feeder - belt conveyor - Anqian dressing factory warehouse). The company has a total of two sets of the tape system. Xu Donggou stope is an independent system and Dumb Ling, West Back stope share the other tape system. The mineral processing adopts three-stage crushing with single closed circuit, stage grinding, coarse separation, gravity separation, strong magnetic separation, and anionic reverse flotation. The sketch of distribution and transportation of stopes is shown in Figure 1:

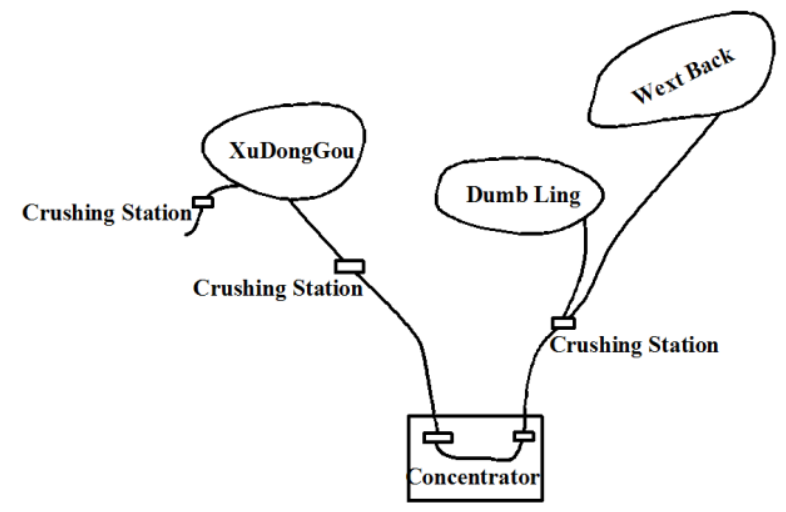

Figure 1. Distribution and transportation of stopes.

* Corresponding Author: L.J. Guo, guolianjun@ ustl.edu.cn, phone: +86 412-5928007

Copyright $\odot 2017$ Canamaple Academia Services, http://press.camdemia.ca

DOI: 10.15273/gree.2017.02.009 


\section{Analysis of Ore Quality and Processability}

As a joint mining venture, Anqian mining company provides most of the ore to the concentrating mill for iron concentrate production and sells another part of ore to Qidashan processing plant. The main recovery element of iron ore is iron in Anqian mining area and the content of accompanying elements did not reach the standard of comprehensive recovery. The harmful sulfur and phosphorus ingredients are not high but the content of silicon dioxide is high. The mineral composition of iron ore in Anqian district is roughly the same, which can be divided into three types of hematite quartzite, magnetite quartzite and false hematite quartzite. Hematite quartzite is steel grey to brown grey and grey red with thin banded structure and is distributed on the surface and shallow seams. Most of the magnetite quartzite is mainly composed of primary ore which is mostly distributed in deep deposits. False hematite quartzite is mainly of thin banded structure and fake like structure, which accounted for a smaller proportion of such minerals in this area (Li et al 2012).

Blending optimization not only requires the optimization in the mining process, but also must satisfy the requirement of concentrator processing capacity, mine production and grade control to realize the stable output of iron concentrate at a constant rate of production with expected grade. So the ore optional of different location must be studied and feedback the optional index to the raw ore blending model.

According to the statistical data of many years (Qiu et al 2009), selected types of ore have a corresponding relation between the grinding time, the sorting index, the ball mill, comprehensive concentrate grade and the comprehensive tailings grade index in Anqian mining company. The relationship shows (Wang et al 2016) when ore dressing experiment for the grinding time is less than 20 minutes, the concentrate grade can reach 58\% and concentrate yield reached $15 \%$, then ore dressing plan can be realized - the ball mill is $248 \mathrm{t} / \mathrm{h}$, the comprehensive concentrate grade is $7.5 \%$, and the grade of comprehensive tailings is about $10.2 \%$. When the ore is mined from different parts, the blending ore optional indices in the test can be calculated by following rules.

Grinding time $\quad t=\sum\left(t_{i} p_{i}\right)$

Comprehensive concentrate grade $\beta=\sum\left(\beta_{i} p_{i}\right)$

Concentrate yield $r=\sum\left(r_{i} p_{i}\right)$

In the formula, $i$ is the number of mining area, $p$ is the proportion of ore.

In order to ensure the specified grade of concentrate, a concentrate grade of less than $54 \%$ in separability test should be strictly controlled, and shall not exceed the limit by $5 \%$. Through the indoor test of magnetic tube, the separability of different grade ore was analyzed, and the grinding time, concentrate grade and concentrate yield were measured, thereby, the corresponding relationship between the indices of ore processability test and production indices was developed and the results are shown in Tables 1 and 2.
Table 1. The optional test indices of raw ore.

\begin{tabular}{ccccc}
\hline No. & $\begin{array}{c}\text { The } \\
\text { grade of } \\
\text { raw ore } \\
(\%)\end{array}$ & $\begin{array}{c}\text { Grinding } \\
\text { time } \\
(\mathrm{min})\end{array}$ & $\begin{array}{c}\text { Fine ore } \\
\text { grade of } \\
\text { magnetic } \\
\text { tuber } \\
(\%)\end{array}$ & $\begin{array}{c}\text { Fine ore } \\
\text { yield of } \\
\text { magnetic } \\
\text { tuber }(\%)\end{array}$ \\
\hline 1 & $22-24$ & $15-20$ & $59-61$ & $15-20$ \\
\hline 2 & $22-26$ & $20-25$ & $58-60$ & $20-25$ \\
\hline 3 & $22-26$ & $20-25$ & $56-58$ & $20-25$ \\
\hline 4 & $24-26$ & $26-28$ & $52-54$ & $25-30$ \\
\hline 5 & $24-28$ & $20-25$ & $58-60$ & $25-30$ \\
\hline 6 & $26-30$ & $15-20$ & $59-61$ & $30-35$ \\
\hline 7 & $26-30$ & $15-20$ & $59-61$ & $35-40$ \\
\hline
\end{tabular}

Table 2. Indices of ore dressing.

\begin{tabular}{cccc}
\hline No. & $\begin{array}{c}\text { Hourly } \\
\text { throughput per } \\
\text { mill }(\mathrm{t} / \mathrm{h})\end{array}$ & $\begin{array}{c}\text { Concentrate } \\
\text { grade }(\%)\end{array}$ & $\begin{array}{c}\text { Tailings } \\
\text { grade } \\
(\%)\end{array}$ \\
\hline 1 & $240-250$ & 67.5 & $10-10.5$ \\
\hline 2 & $230-240$ & 67.5 & $10-10.3$ \\
\hline 3 & $220-230$ & $67-67.5$ & $10-10.5$ \\
\hline 4 & $220-230$ & $66-66.5$ & $11-12$ \\
\hline 5 & $230-240$ & 67.5 & $9.8-10.2$ \\
\hline 6 & $240-250$ & $67.5-68$ & $9.2-9.6$ \\
\hline 7 & $235-245$ & $67.5-68$ & $8.8-9.2$ \\
\hline
\end{tabular}

\section{The Establishment of Ore Blending Optimization Model}

\subsection{Optimization of ore blending model with the minimum transportation work}

(1) Objective function

According to the actual situation of the mine, a total of three mines participate in ore blending at the same time. It is assumed that there are $i$ blasting piles waiting to be mined in ore blending, the distance from the $i$ th blasted muckpile to the crushing station is $l_{i}, m$ indicates whether to choose this mine, $m \in[0,1], 1$ means selected, 0 means not selected. Assuming that the amount of ore to be mined from the $i$ th muck-pile is $x_{i}$, the transportation work is $\mathrm{W}$, the goal of mining is to achieve the minimum transport power under the premise of meeting the target grade. The objective function is expressed as:

$$
\operatorname{Min} W=\sum_{i=1}^{\mathrm{K}} m x_{i} l_{i}(i=1,2,3 \ldots, \mathrm{K})
$$

where, $\mathrm{K}$ means the total number of muckpiles participating in blending for the three opencasts.

(2) The constraint of ore quantity of each muckpile

Due to the limitation of the maximum production capacity of electric shovel $c_{s}$, the maximum amount of 
digging from each pile could not be more than the maximum production capacity of electric shovel. The blasting pile participating in blending must ensure mine output.

$$
\begin{aligned}
& m x_{i} \geq 0 \\
& x_{i} \leq c_{\mathrm{s}} \quad i=1,2 \cdots, K
\end{aligned}
$$

(3) The constraint of the total output of each opencast stope Taking into account the requirements of advance mining of open pit and mining continuity, the total amount of ore mined in each stope shall not exceed the maximum limit of exploitation of the stope and shall not be less than the minimum limit of exploitation. $\mathrm{n}=1,2,3$ said $\mathrm{Xu}$ Donggou Mute ridge and West big dumb respectively, and specific constraints are as follows:

$$
\begin{aligned}
& m_{n} \leq \sum_{i=1}^{k_{0}} m x_{i} \leq M_{n} \quad n=1, \quad i=1,2,3 \cdots, k_{0} \\
& m_{n} \leq \sum_{i=k_{0}+1}^{k_{1}} m x_{i} \leq M_{n} \quad n=2, \quad i=k_{0}+1, \cdots, k_{1} \\
& m_{n} \leq \sum_{i=k_{1}+1}^{\mathrm{K}} m x_{i} \leq M_{n} \quad n=3, \quad i=k_{1}+1, \cdots, \mathrm{K}
\end{aligned}
$$

(4) Constraint of target grade

The requirements of different crushing stations on the grade are different. It is assumed that the total iron and ferrous iron target grade of each crushing station are respectively $e_{n}$ and the total iron grade for each blasting pile to be mined is $a_{i}$, ferrous grade is $f_{i}$, and the three crushing stations were marked with 1, 2, 3, the specific constraint expressions are as follows:

$$
\begin{aligned}
& \sum_{i=1}^{k_{0}} m a_{i} x_{i}=e_{1} \sum_{i=1}^{k_{0}} m x_{i} \\
& \sum_{i=1}^{k_{0}} m f_{i} x_{i}=p_{1} \sum_{i=1}^{k_{0}} m x_{i} \quad n=1, i=1,2 \cdots, k_{0} \\
& \sum_{i=19}^{36} m a_{i} x_{i}=e_{2} \sum_{i=19}^{36} m x_{i} \\
& \sum_{i=k_{0}+1}^{k_{1}} m f_{i} x_{i}=p_{2} \sum_{i=k_{0}+1}^{k_{1}} m x_{i} \quad n=2, i=k_{0}+1, \cdots, k_{1} \\
& \sum_{i=k_{1}+1}^{K} m a_{i} x_{i}=e_{3} \sum_{i=k_{1}+1}^{K} m x_{i} \\
& \sum_{i=k_{1}+1}^{K} m f_{i} x_{i}=p_{3} \sum_{i=k_{1}+1}^{K} m x_{i} \quad n=3, i=k_{1}+1, \cdots, K
\end{aligned}
$$

(5) Constraints of the magnetic rate

In order to ensure the balance of total iron and ferrous during ore blending, magnetic rate needs to be restricted. $a_{i}$ is used to express the total iron grade, and $f_{i}$ is used to express the grade of ferrous iron. The specific expression is as follow:

$$
\frac{a_{i}}{f_{i}} \geq 18 \quad i=1,2 \cdots, K
$$

\subsection{Concentrate control model}

The optimal blending model of transportation work minimizing is suitable for mines with little difference in selectivity. But for the combined mining and beneficiation enterprise like Anqian company, the ultimate goal of blending optimization is profit maximization in the whole life cycle of mine, or the available resources utilization maximization by the economic way.

(1) The objective function is to maximize the total concentrate output.

$$
\operatorname{Max} P=S \sum Q_{i} r_{i}-\sum Q_{i}\left(d_{i}+g_{i}\right)
$$

(2) Constraints

$$
\left\{\begin{array}{l}
Q=\sum Q_{i} \\
Q_{i} \leq M_{i} \\
p_{i}=\frac{Q_{i}}{Q} \\
\beta=\frac{\sum \beta_{i} Q_{i} r_{i}}{\sum Q_{i} r_{i}} \geq 58 \% \\
d_{i}=\lambda_{d} F_{1}\left(l_{i}\right) \\
g_{i}=\lambda_{g} F_{2}\left(t_{i}\right) \\
T=\sum t_{i} p_{i} \leq 20
\end{array}\right.
$$

when $\beta \leq 54 \%$, then $p_{i} \leq 5 \%$

In the above formula,

P - Whole profit;

$\mathrm{d}_{\mathrm{i}}$ - mining cost;

$\mathrm{g}_{\mathrm{i}}$ - processing cost;

$\lambda_{\mathrm{d}}, \lambda_{\mathrm{g}}$ - adjust indices mining and processing cost;

$\mathrm{F}_{1}, \mathrm{~F}_{2}$ - functions for mining and processing cost;

$M_{i}$ - The amount of ore can be mined;

$r_{i}$ - Concentrate yield;

$Q_{i}$ - Raw ore production;

$Q-$ The total amount of raw ore mining;

$\beta$ - Concentrate grade;

$T$ - Comprehensive grinding time;

$t_{i}$ - Grinding time; 


\section{Algorithm Analysis and Implementation}

Resource allocation optimization about coordinated mining of multiple mining areas in open pit mine is a linear programming problem. But the model does not fully conform to the standard of simplex method, because of the specific constraints and other reasons. So, big M method of simplex is well suitable for solving this kind of problem.

\subsection{Big M method}

The large $\mathrm{M}$ rule is to construct an auxiliary linear programming problem by adding some artificial variables to the original constraint equation as dummy variables. It is obvious that there is a basic feasible solution to this planning problem. Then these dummy variables are replaced from the base variables. For this purpose, a very large positive $\mathrm{M}$ will be introduced to control the value of artificial variables (Xiong,2014). Then the standard objective function of the simplex big $\mathrm{M}$ method can be described as follows:

$$
\max F=\sum c_{i} x_{i}-M \sum x_{j}
$$

where $\mathrm{x}_{\mathrm{j}}$ is artificial variable. Because $\mathrm{M}$ is a very large number, so only when $x_{i}=0, \mathrm{~F}$ can get the maximum value. At the same time, the introduction of the artificial variable has no effect on the solution of the original problem.

\subsection{The calculation steps of big $M$ method}

(1) Convert it to the standard form of simplex method, and introduce artificial variable, to construct the unit matrix;

(2) Finding an initial basic feasible solution;

(3) Determine whether the basic feasible solution for the optimal solution, inspection criteria is as follows:

The test number $\partial_{i}=c_{i}-c_{B} B^{-1} p_{i}$ corresponding to the non-

base variable $x_{i}$ is less than or equal to 0 .

If all $\partial_{i} \leq 0$, stop calculation, the optimal solution obtained, otherwise turn to step (4);

(4) Iteration (find the next feasible solution)

Searching for a base variable, namely, a non base variable is transformed into a base variable. The principle of selection is to find the maximum number of tests in all the tests:

$$
\max \left\{\partial_{i} \mid \partial_{i}>0\right\}=\partial_{k}
$$

Then $x_{k}$ is converted from a non-base variable to a base variable.

Since there is a non base variable into a base variable, there is a base variable that becomes a non base variable as well. Selection principle is:

$$
\min \left\{\frac{b_{i}}{a_{i k}} \mid a_{i k}>0\right\}=\frac{b_{l}}{a_{l k}}
$$

Then, the original $l$ th basis variable is transformed into a non-base variable, and the base matrix and the non base matrix will be updated. $a_{l k}$ is the principal element, that is, in the process of finding the next feasible solution, the row of $a_{l k}$ located in the matrix should be considered first, and find the constraint equation. By means of the coefficient transformation, a new basic feasible solution is obtained by constructing a unit matrix with other row coefficients, and then jump back to step (3).

According to the above algorithm steps, the algorithm flow chart is shown in Figure 2.

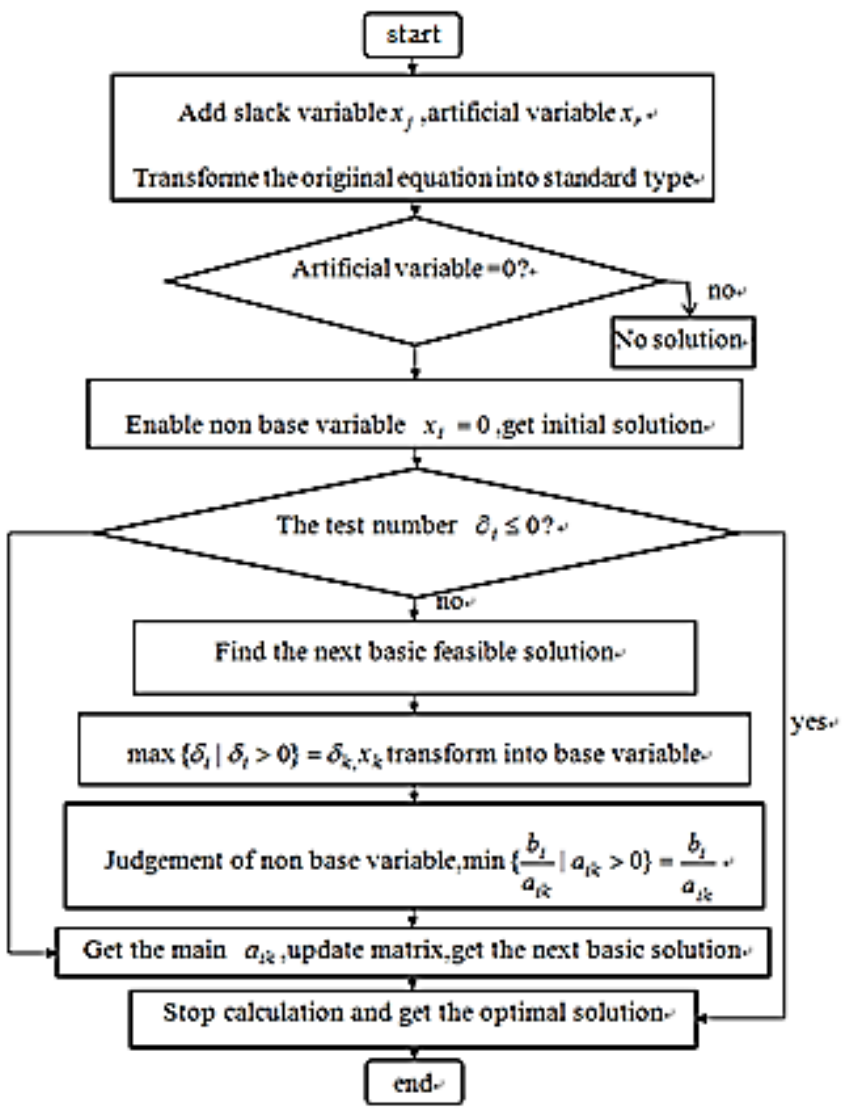

Figure 2. Flow chart of optimization algorithm.

\section{Conclusions}

Based on the introduction of Anqian mining company production process, the distribution of ore quality was discussed in detail. Through the indoor test of magnetic tube, the processability of different grade ore was analyzed, and grinding time, concentrate grade and concentrate yield were measured. On the basis of established digital geological model of the deposit (Pan et al 2016), two stage blending optimization models were established. In the first stage of the model, the target is the minimum of ore transportation work while meeting the conditions of the grade of raw ore output and production of stopes. The second stage was a system optimal model and the target is to maximize the profit of the company under the condition that the production process constraints of mining and dressing, requirements for ore beneficiablity and grade of concentrate should be satisfied. In this paper, the nonlinear solution of the model and its realization in production were analyzed and proposed. The method has been applied to Anqian mining company successfully. 


\section{References}

Lei, P.X., 2011. Support the steel industry comprehensive, balanced and sustainable development. China metallurgical mines yearbook, Metallurgical Industry Press, 16 - 17.

Li, Z.Q., J.H. Xu, K. Guo and L. Zhao, 2012. Properties of Ansteels Iron ore resources and their high-effective exploitation. Mining Engineering, 10(6): 25 - 28.

Pan, P.F., H.G. Sun, C. Yang, C.Y. Li and L.H. Luan, 2016. Establishment and application of 3D stopes model in Anqian mine. Science and Technology, (28): 20 - 22.

Qiu, J.P., J. Xing, A.Q. QV and X.G. Sun. 2009. Study on rock characteristics of Anqian iron mine. Non-ferrous Metals (Mining Section), 61(2): 24 - 27.

Wang, L.Y., Q.F. Wu and C.Y. Li. 2016. Research of technological mineralogy of Xidabei mining area's ore of Anqian mining Co., Ltd. Mining Engineering, 14(3): 18 - 22. DOI: 10.16672/j.cnki.kygc.2016.03.013

Wang, Y. and M. Zhao, 2013. Research of production and ore-matching in digital mine based on Dmine. Metal Mine, Series No. 446(8): 101 - 103.

Xiong, W., 2014. Operations research. China Machine Press, Beijing, 35 - 50.

Zhang X., 2014. Research on the development and utilization of low grade iron ore resources. A Dissertation Submitted to China University of Geosciences for Master Degree, 41 - 50.

Zhu L. and Q. Li. 2014. Present situations on studying and utilizing low grade iron ore in our country. Science and Technology of Baotou Steel, 40(6): 76 - 78. DOI: 10.13647/j.cnki.btgkj.2014.06.026 